ASLI QoL 2021

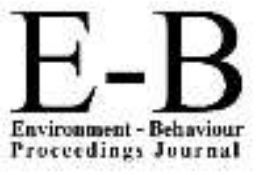

\title{
AQoL2021LangkawiIsland
}

https://www.amerabra.org; https://fspu.uitm.edu.my/cebs; https://www.emasemasresources.com/

$5^{\text {th }}$ ABRA International Conference on Quality of Life

Holiday Villa Langkawi, Langkawi Island, Malaysia, 15-16 Dec 2021

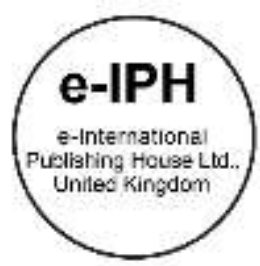

\section{Factors Affecting the Visitation and Non-Visitation to the Courtyard Gardens: Evaluation at three Malaysian public hospitals}

\author{
Madihah Mat Idris' ${ }^{1}$ Magda Sibley², Karim Hadjri³ ${ }^{3}$ Azhani Abd Manaf ${ }^{4}$ \\ 1 Department of Architecture, Faculty of Engineering and Built Environment (FKAB), Universiti Sains Islam Malaysia (USIM), Malaysia, ${ }^{2}$ \\ Welsh School of Architecture, Cardiff University, Cardiff, United Kingdom; ${ }^{3}$ School of Architecture, Faculty of Social Sciences, University \\ of Sheffield, Sheffield, United Kingdom, ${ }^{4}$ Department of Architecture, Faculty of Engineering and Built Environment (FKAB), Universiti \\ Sains Islam Malaysia (USIM), Malaysia.
}

Email of all Authors: madihahidris@usim.edu.my, SibleyM@cardiff.ac.uk, k.hadjri@sheffield.ac.uk, azhani@usim.edu.my Tel Author1: -

\begin{abstract}
Being in a natural setting and viewing nature have a significant effect on mental health and well-being. Hospital courtyard gardens (HCG) is a common feature found in public hospitals in Malaysia. However, what factors influence the visitation and non-visitation to the HCG are less understood. This study investigates factors influencing the visit and non-visitation of patients, staff and visitors to the HCGs in three Malaysian public hospitals. The research findings were instrumental to the architects and landscape architects to make necessary improvements for future HCG design and the hospital managers to enhance and retrofit the existing HCG.
\end{abstract}

Keywords: Courtyard Gardens; Visitation; Non-visitation, Public hospital

eISSN: 2398-4287@ 2021. The Authors. Published for AMER ABRA cE-Bs by e-International Publishing House, Ltd., UK. This is an open access article under the CC BYNCND license (http://creativecommons.org/licenses/by-nc-nd/4.0/). Peer-review under responsibility of AMER (Association of Malaysian Environment-Behaviour Researchers), ABRA (Association of Behavioural Researchers on Asians/Africans/Arabians) and CE-Bs (Centre for Environment-Behaviour Studies), Faculty of Architecture, Planning \& Surveying, Universiti Teknologi MARA, Malaysia.

DOI: https://doi.org/10.21834/ebpj.v6i18.3085

\subsection{Introduction}

People's health and well-being have been affected by the quality of the environment they live and work in. Long hours spent in a sterile hospital environment can be stressful for patients, staff, and visitors. Contact with nature (either by having a view of a garden or being in a garden) has been shown to have a positive impact on patients' recovery, mainly because nature aids in relaxation and stress reduction in humans, hence improving people health and well-being (Ulrich et al., 2018; Amat, 2017; Gonzalez et al., 2011; Kim et al., 2009; Verderber and Reuman,1987; Ulrich, 1984). Thus, having access to natural settings in hospital buildings can improve health outcomes and stress coping abilities (Ulrich et al., 2020; 2018; Cooper Marcus and Sachs, 2014). Furthermore, as reported in several interventional studies, interaction with nature, whether being in a natural setting or walking through nature, positively impacts stress levels in adult patients (Kim et al., 2009; Gonzalez et al., 2011).

Courtyard gardens were incorporated into the built form of hospital buildings not only to provide comfort by improving the microclimatic conditions (Idris et al., 2019; Almhafdy et al., 2013b; 2014) but also provided restorative environments that facilitated their well-being (Idris et al., 2018; Cooper Marcus and Barnes, 1995; Naderi and Shin, 2008). Regardless of the garden's positive effect on people's well-being, several scholars have argued that the outdoor gardens in Malaysian hospitals do not adequately consider their restorative functions (Shukor, 2007; Adnan, 2016). However, the limitation of this study is that they concentrated on all types of outdoor gardens in a single-

eISSN: 2398-4287@ 2021. The Authors. Published for AMER ABRA cE-Bs by e-International Publishing House, Ltd., UK. This is an open access article under the CC BYNCND license (http://creativecommons.org/licenses/by-nc-nd/4.0/). Peer-review under responsibility of AMER (Association of Malaysian Environment-Behaviour Researchers), ABRA (Association of Behavioural Researchers on Asians/Africans/Arabians) and CE-Bs (Centre for Environment-Behaviour Studies), Faculty of Architecture, Planning \& Surveying, Universiti Teknologi MARA, Malaysia.

DOI: https://doi.org/10.21834/ebpj.v6i18.3085 
case hospital and did not explicitly focus on courtyard gardens in multiple case study sites. Most studies have concentrated on the general type of outdoor environment in a hospital, with a particular emphasis on sick children (Said et al., 2005; Shukor, 2007; Pasha, 2013; Samad and Rahim, 2014) and had an insufficient response from the diverse user groups (patients, staff, visitors) in the public hospital which is the focal point of this study.

Most of the previous studies on the outdoor gardens in a hospital focused solely on the users' perspectives (Tseung et al., 2021; Karanikola et al., 2020; Sachs, 2019; Dukanovic et al., 2017). A small amount of research has been conducted on the non-users perceptions of an outdoor garden in a hospital (Pasha, 2013). This current study also assesses non-users views to avoid sampling bias and reporting. This issue has been singled out by Cooper Marcus and Barnes (1995), and Shukor (2012) emphasised the importance of non-participant perceptions to avoid bias in data collection and reporting processes. To date, a study on the factors affecting the visit and non-visitation to the HCG in Malaysian public hospitals remain scarce. Understanding from the perspectives of HCG users and non-users is fundamental to examining matters that entice them to visit the HCG and issues that prevent them from visiting the HCG. Therefore, this study aimed to identify factors that resulted in the visitation and non-visitation of patients, staff, and visitors to the HCGs in three Malaysian public hospitals. This study is vital to assess the components of an effective HCG design, develop the HCG framework, and provide recommendations for policy and practice.

\subsection{Literature Review}

\subsection{Theoretical foundations of restorative environments}

A restorative environment is defined as a setting that can 'promote (rather than simply permit)' restoration and recovery from the mental exhaustion of daily errands and excessive demands, resulting in positive outcomes such as improved moods, lower stress levels, cognitive function renewal, and psychological well-being (Hartig, 2004, p.273-274). A substantial amount of empirical and scientific research has demonstrated the benefits of interaction with nature in terms of stress restoration and the beneficial effect it can have on health outcomes in either healthcare (Ulrich, 1984; Verderber and Reuman, 1987; Kim et al., 2009; Gonzalez et al., 2011) or non-healthcare settings (i.e., urban setting) (Ulrich, 1981; Ulrich et al., 1991; Thompson et al., 2012; Honold et al., 2016).

The theory of restorative environments is traditionally referred to as the 'Biophilia' concept. It is associated with the restorative process, health-related effects, and benefits to human outcomes gained through interaction with nature (Wilson, 1984). This theory implies that humans tend to develop a positive response to nature. Ulrich (1984) expanded on this theory, suggesting that a positive response also includes restoring psychological aspects based on stress reduction (Stress Reduction Theory - SRT). Kaplan and Kaplan (1989) recommended that a positive response from nature facilitates the psychological restoration process by regaining direct attention (Attention Restorative Theory - ART). Numerous empirical studies have been conducted to substantiate both SRT (Ulrich et al., 1991; Hartig and Staat, 2004) and ART (Berto, 2005; Staats et al., 2003).

Moreover, previous studies reported that contact with nature (e.g., plants, flowers, water, wildlife) in the outdoor garden is a positive distraction for many users as nature can fascinate and restore people's minds (Cooper Marcus and Sachs, 2014). The majority reported a better and positive mood shift after spending time there (Cooper Marcus and Sachs, 2014). A recent study using randomised controlled experiments with virtual reality (VR) applications investigated the effect of trees, grass and concrete elements in the built environment on people physiological restoration and psychological well-being (Huang et al., 2020). This study revealed that the natural environment has a more substantial restorative effect than the concrete environment without vegetation (Huang et al., 2020). Additionally, a recent study suggested that fascinating greenery environments such as healing gardens contribute to positive emotions such as joy and pleasure among the visitors and impact their level of satisfaction and encourage them to revisit the garden (Jang et al., 2020). A recent study discovered that family members of ICU patients preferred to take a break in the garden because it reduced their stress more than taking a break in the atrium café or indoor waiting area (Ulrich et al., 2020).

\subsubsection{Stress Reduction theory (SRT)}

The underlying principle of SRT suggests that the potential of natural environments to improve health outcomes is linked to an individual's ability to manage stress and restore good psychological well-being. (Ulrich, 1984, 1991). This theory which is also referred to as the 'theory of supportive gardens' (Ulrich, 1999), suggests that an outdoor garden in a healthcare setting can serve as a stress-relieving resource if it is designed to promote the following characteristics: (1) a sense of control; (2) social support; (3) physical movement and exercise; and (4) access to natural distractions (See Figure 1). The Theory of Supportive Gardens by Ulrich (1999) encompasses the effects of outdoor gardens on health outcomes in a healthcare setting. It consists of four characteristics that can foster specific restorative and coping resources that result in stress reduction and improved health outcomes. 


\section{STRESS REDUCTION THEORY (SRT)}

(Source: Ulirich, 1984; 1999)

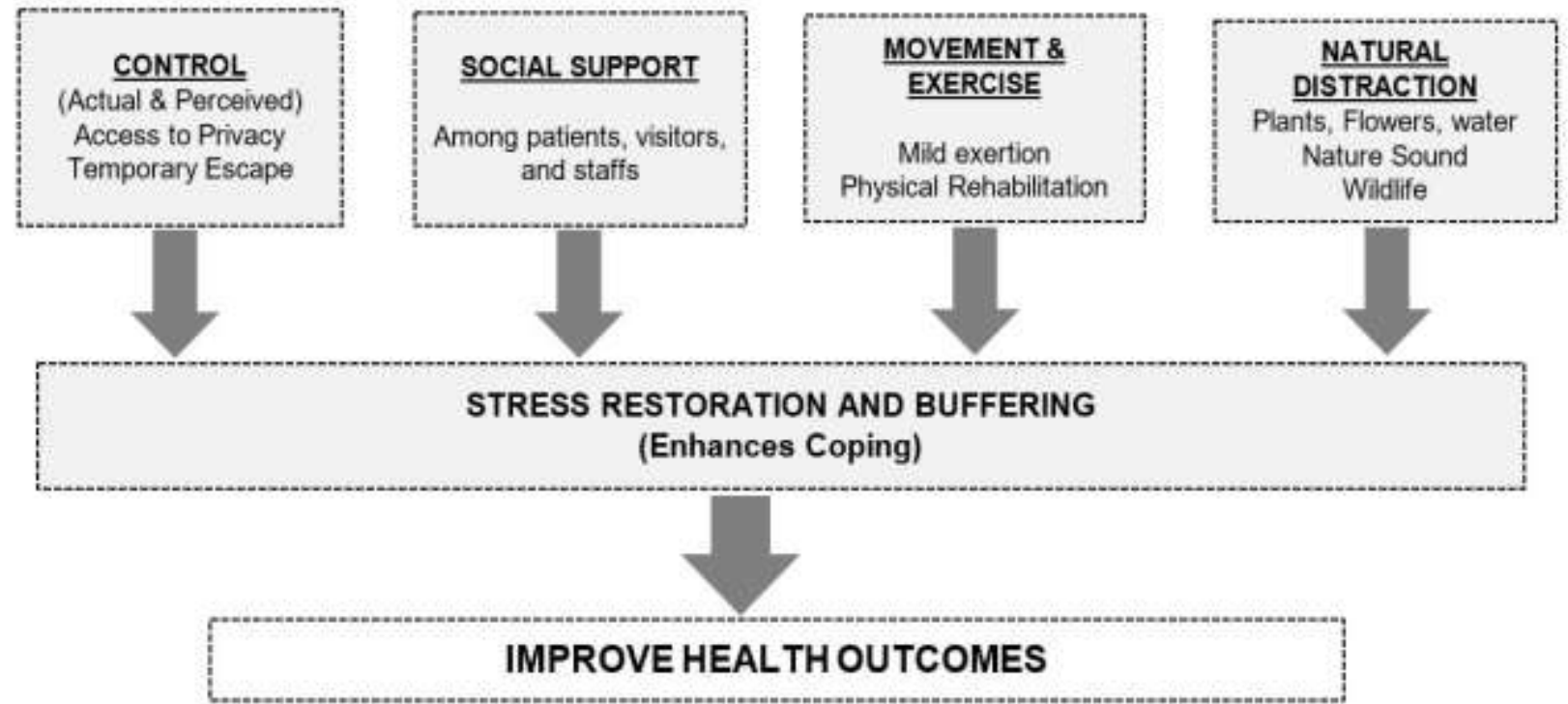

Figure 1: Conceptual model: Effect of the garden on Health outcomes Source: Ulrich (1999) and re-illustrated back by Author (2017).

\subsubsection{Attention Restorative Theory (ART)}

Apart from Ulrich (1999) theory which emphasised stress alleviation in the medical setting, ART suggested that interaction with the natural environment can have a positive effect in fostering recovery from the depleted directed attention capacity (Kaplan and Kaplan, 1989; Kaplan 1995). According to Kaplan and Kaplan (1989), ART concentrated on the two types of attention associated with the human's brain function: 'Direct Attention' and 'Indirect attention (Cooper Marcus and Sachs, 2014, p.28-29). 'Direct attention' refers to a persistent concentration in carrying out a demanding or stressful task, indirectly disrupting the sensory stimuli and causing mental fatigue. This theory suggests that 'indirect attention' can facilitate the recovery process after a period of prolonged mental fatigue. Indirect attention is a state of mind that does not necessitate any effort to alleviate mental fatigue (Kaplan and Kaplan, 1989; Kaplan, 1995) in which refer to the terms 'soft fascination' that aids mental restoration and helps cope with anxieties and alleviate stress. Kaplan and Kaplan (1989) asserted that direct or indirect contact with nature (via viewing or being in a garden) can contribute to positive well-being (Cooper Marcus and Sachs, 2014, p.28-29). ART identifies four fundamental characteristics of restorative settings: (1) Being away; (2) Extent; (3) Fascination; and (4) Compatibility (See Figure 2).

\section{ATTENTION RESTORATIVE THEORY (ART)}

(Source: Kaplan and Kaplen, 1988, Kaplan, 1895)

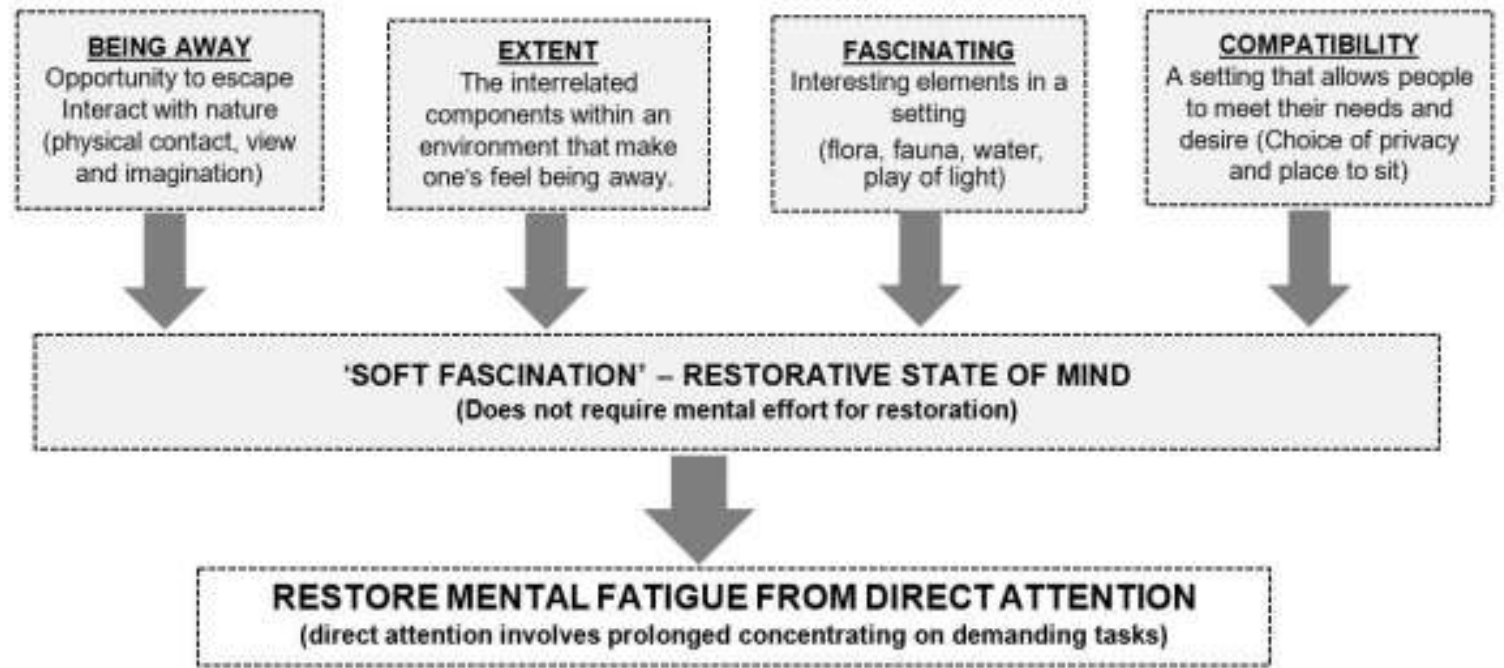

Figure 2: Conceptual model diagram: component of restorative environment Source: Kaplan and Kaplan, 1989; Kaplan 1995). A diagram is illustrated by Author (2017). 
Both SRT and ART theory are the central point of this research because these theories emphasise the interaction of humans with nature and the role of the natural environment in promoting stress recovery, reducing mental fatigue and contributing to positive feelings through fascination and reflection (See Figure 3).

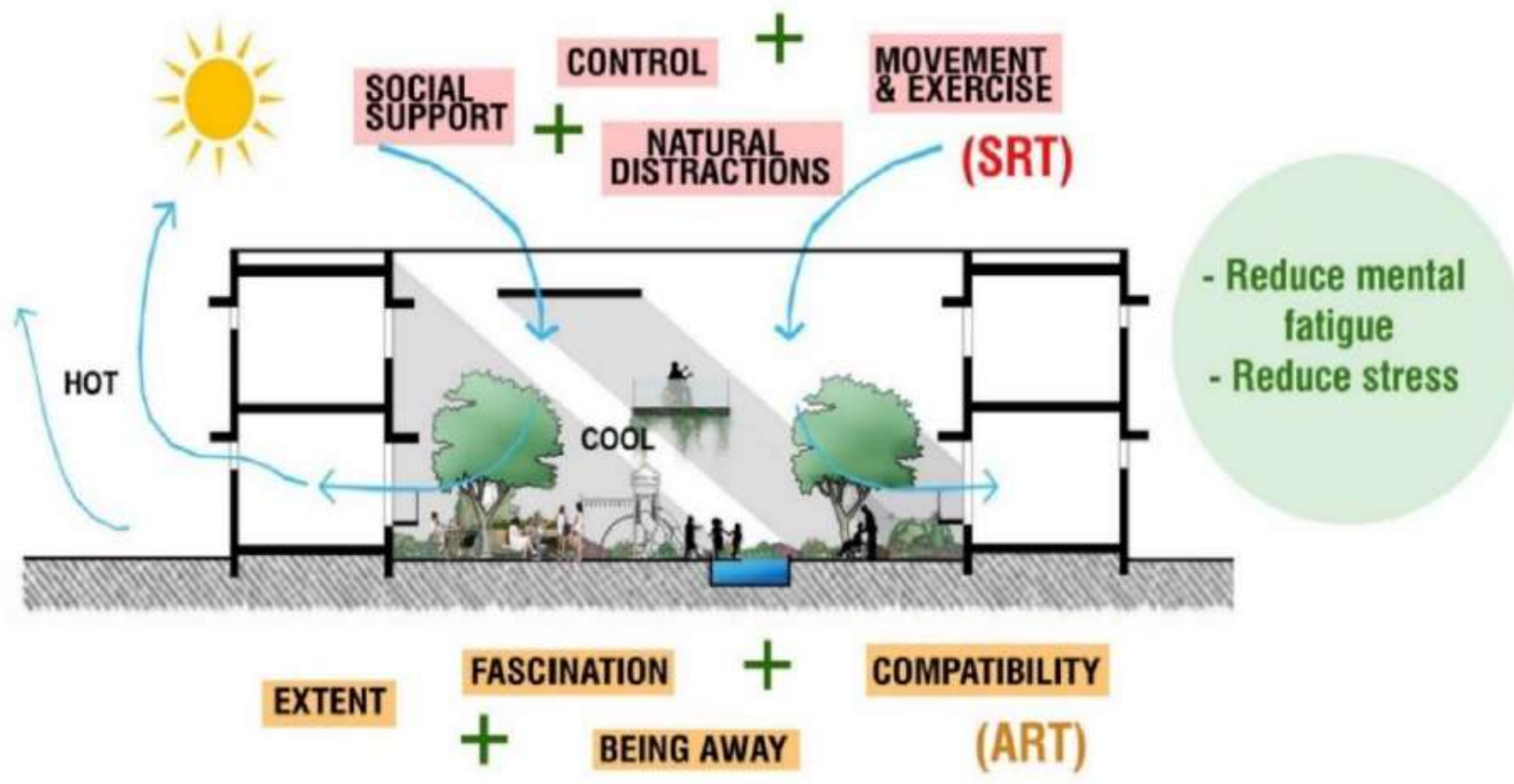

Figure 3: Illustration indicates the criteria for a restorative environment for the outdoor garden in the hospital. Source: Idris (2020)

\subsection{Methodology}

\subsection{Study area}

Three representative samples of three different HCGs were selected from three Malaysian public hospitals (H1-hospital, H2-hospital, and H3-hospital) located in Johor Bharu, Selangor, and Kedah, respectively (See Figure 4). Before the actual fieldwork, ethical research approval was obtained from the Medical Research Ethics Committee (MREC) under the Malaysian Ministry of Health (MOH) and the hospital manager of each case study hospital. Between January and March 2018, fieldwork was first carried out at the H3 hospital, then at the $\mathrm{H} 2$ and $\mathrm{H} 1$ hospitals (i.e. $\mathrm{H} 3$-hospital received earlier approval from the hospital manager).

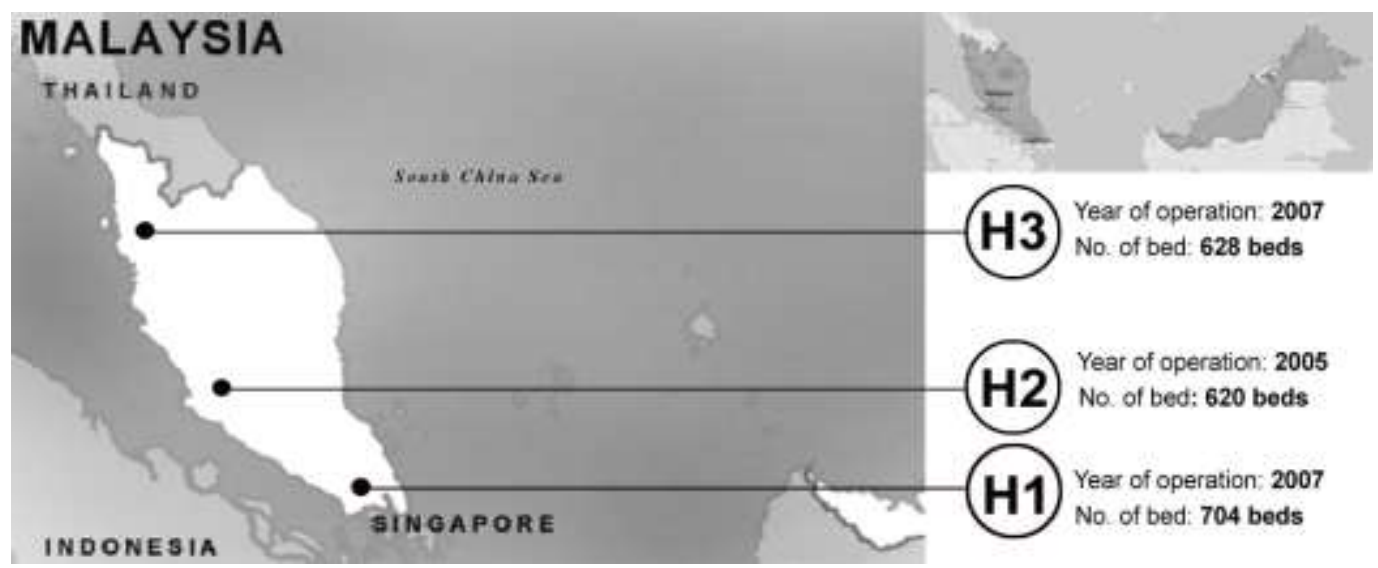

Figure 4: Location of the three case study hospitals: $\mathrm{H} 1, \mathrm{H} 2$ and $\mathrm{H} 3$.

The selected case study hospitals $(\mathrm{H} 1, \mathrm{H} 2$ and $\mathrm{H} 3)$ were chosen to represent all types of closed courtyard garden configurations. Due to the feasibility of the case study sites, time constraints, and budget, the research was limited to Peninsular Malaysia and State Government hospitals with bed capacities ranging from 500 to 700 beds. The site visits and field investigation were carried out in all 13 
HCGs in all the three case study hospitals to ensure the best selection of three representative case study HCGs. The selection of the three representative case study HCGs was based on the 6 following criteria: i) accessibility; ii) types of users; iii) level of occupancy; iv) feasibility for the subjective assessment study; v) character of the sites (i.e., the availability softscape and hardscape), and vi) the location and space function. Figure 5 shows the selected case study HCGs: H1-C1, H2-C3 and H3-C2.

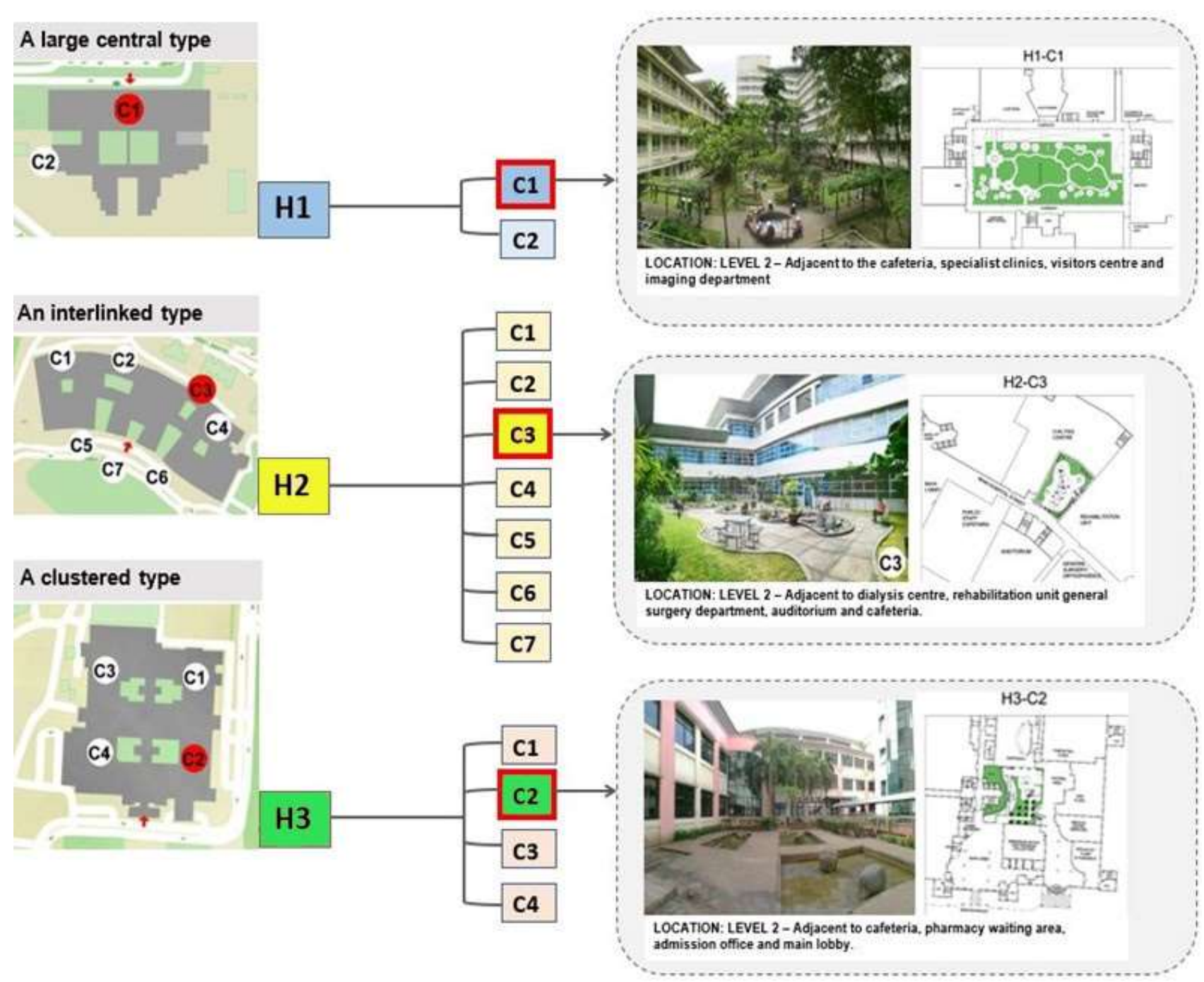

Figure 5: The selection of the representative case study HCGs: $\mathrm{H} 1-\mathrm{C} 1, \mathrm{H} 2-\mathrm{C} 3$ and $\mathrm{H} 3-\mathrm{C} 2$.

Source: Idris (2020, p.140)

\subsection{Survey interview with the group of users and the non-users}

Prior to the actual survey data collection, a pilot test was carried out to test the methods used for the survey data collection and improvements on the survey questions and procedures were made. A face-to-face survey interview with the group of users and non-users was carried out in this study because it obtained a higher responses rate and minimised the nonresponse error compared to the distributed pencil-and-paper survey. The users' group includes those who were sitting and spending time in the HCG. In contrast, the non-users group are among those who were sitting in the lobby or waiting areas in the hospital. Survey research is essential for this study because it allows us to understand people's attitudes, trends, and opinions by studying a representative sample of the population; it also provides the quantitative data that is required as part of the case study evidence (Creswell, 2015). For this study, participation of non-users is required to avoid any bias in the data collection process and subsequent reporting of the results. A simple random sampling was used to select the representative samples for both the HCG users' and non-users' groups in each representative case study HCG (H1-C1, H2-C3 and H3$\mathrm{C} 2$ ). This implied that every member of the population had an equal chance of being selected during the sampling process.

\subsection{Participants recruitments and procedures}

A survey interview with a total of 120 users in all three sites $(\mathrm{H} 1-\mathrm{C} 1(\mathrm{~N}=46)$; $\mathrm{H} 2-\mathrm{C} 3(\mathrm{~N}=36)$; and $\mathrm{H} 3-\mathrm{C} 2(\mathrm{~N}=38)$ were carried out to examine the factors affecting them to visit the HCG. The highest number of samples obtained in the HCG was from the visitors' group, followed by staff than patients (See Table 1). An interview survey was carried out among the participants who had provided consent and were willing to participate in the study. Those who were simply passing by and who were in a state of stress were not approached. The respondents 
who were spending time in the HCG from 9 am to $5 \mathrm{pm}$ were interviewed at random during the fieldwork. In addition, a total of 135 respondents among the non-users group from all three case study hospitals participated in the survey interviews: $\mathrm{H}$ 1-hospital ( $\mathrm{N}=45)$; $\mathrm{H} 2$ hospital $(\mathrm{N}=45)$; and $\mathrm{H} 3$-hospital $(\mathrm{N}=45)$. The survey interviews with the non-users group were carried out by the research assistant simultaneously during the interview with the HCG users were conducted by the main researcher. As with the users' group, the visitors represent the highest sample, followed by staff and patients (See Table 2).

Table 1: Demographic data of the users' group in each representative HCG

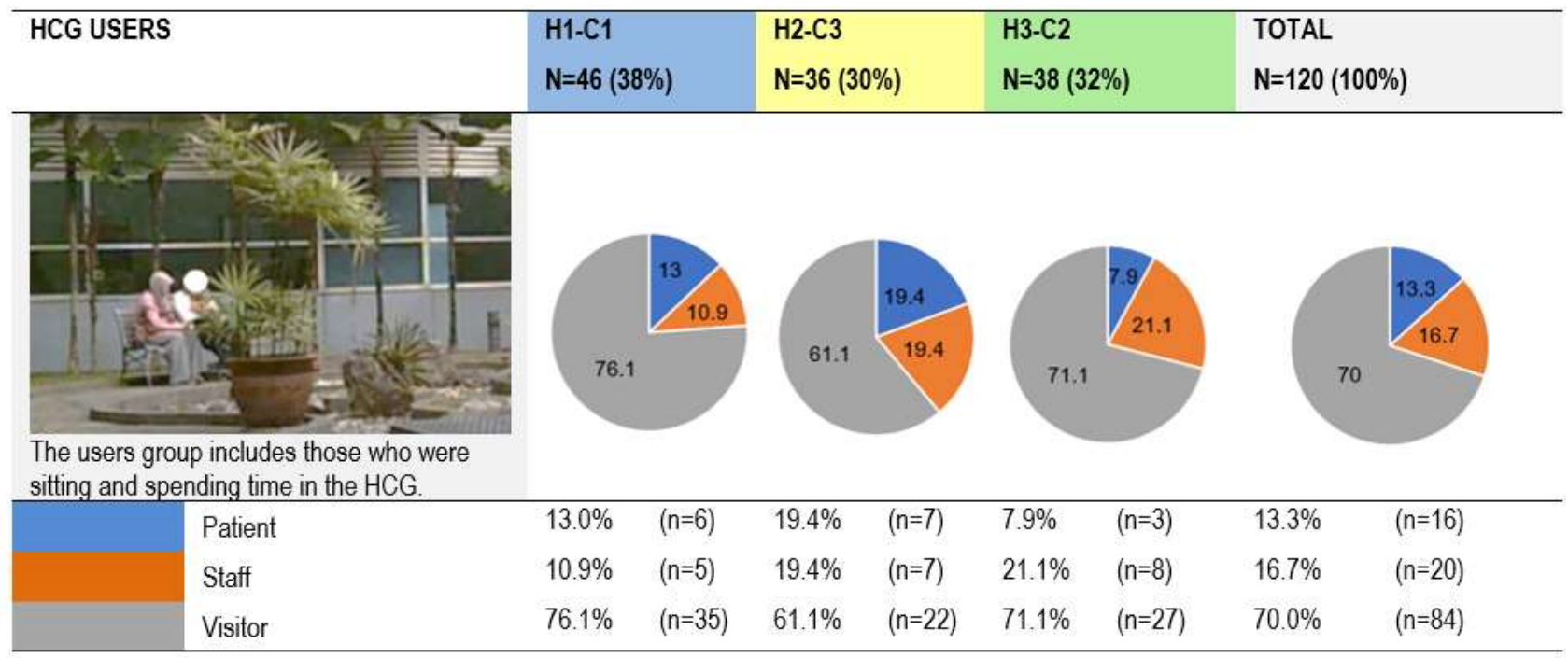

Table 2: Demographic data of the non-users group in each representative HCG

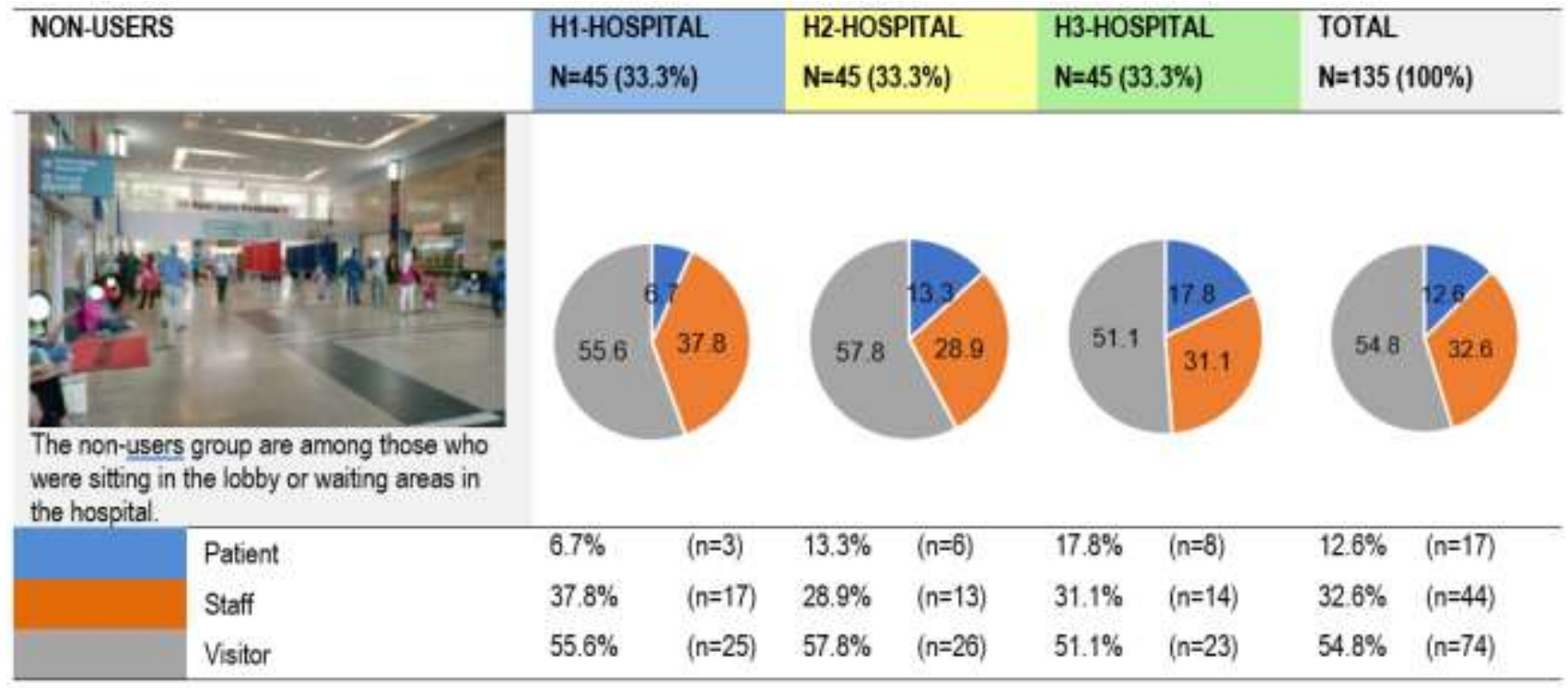

\subsection{Findings}

\subsection{Factors affecting the visitation to the HCG}

For this study, multiple-choice survey questions were used to interview the HCG user group to examine the factors that encourage their visitation to the HCG. The study found that out of a total of 120 respondents that were interviewed, over $50 \%$ of the respondents reported that they wanted to relax and rest, enjoy the view of the courtyard garden, and refresh their minds (See Figure 6). This is following the findings of a previous study in which the respondents mentioned that they liked the HCG because of the availability of a place for them to rest and relax (Idris, 2020). They also mentioned that they favoured the greenery and pleasant views of the HCGs. Additionally, over $20 \%$ of the respondents in all three case study sites visited the HCG because they wanted to contemplate and find some privacy. Other factors that encouraged them to visit the HCG included letting their children play in the HCG, enjoying the outdoor therapy, a refuge that distracted them, coping with their worries, getting away from the everyday routine life, socialising and meeting others, and doing physical exercise. 


\section{Question 19: What encourage you to visit this courtyard garden? $(\mathrm{N}=120)$}

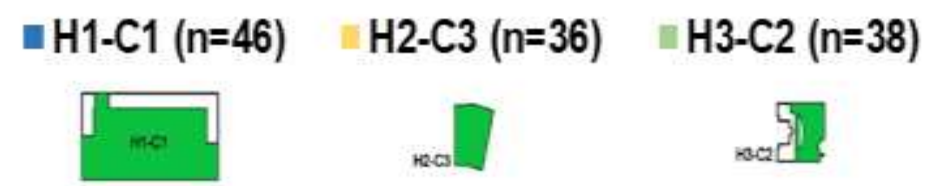

\section{I want to relax and rest}

I want to enjoy the garden

I want to refresh my mind

I want to contemplate and find some privacy

I want to enjoy the outdoor therapy

I want to let my child to play in the courtyard

I want to refuge from the thing that distract me

I want to get cope with my worries

I want to get away from my everyday routine

I want to socialize and meet with other people I want to do a physical exercise
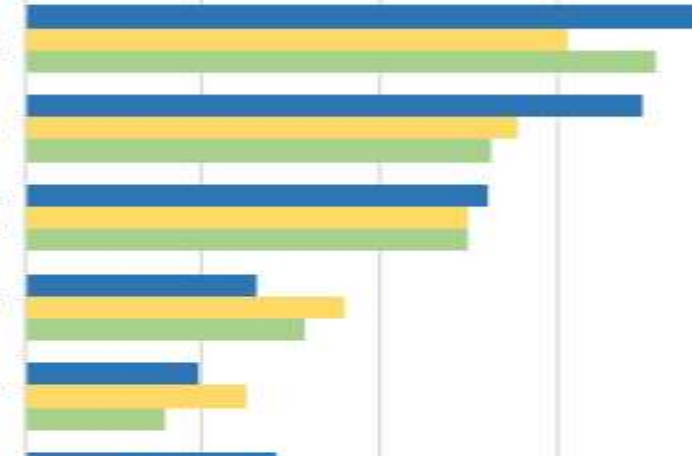

\section{E}

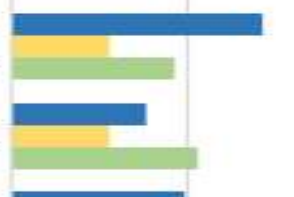

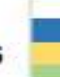

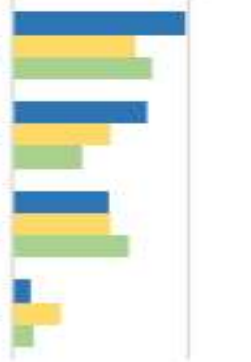

020

40

60

80

Figure 6: Factors affecting visitation to the HCG

\subsection{Factors affecting the non-visitation to the HCG}

Additionally, the non-user group were also asked using multiple-choice questions to assess any factors that refrain them to visit the HCG. A total of 135 respondents participated in this survey. Several key factors that affected their visitation to the HCG included: i) Life routine; ii. Physical design; iii. Accessibility; iv. Safety; and v. Microclimate.

The busy life routines acted as the main barrier to HCG visitation. In total, $42.9 \%$ staff $(n=21), 40.8 \%$ visitors $(n=20)$, and $16.3 \%$ patients $(n=8)$ said they were busy with their daily lives. Visitors to the hospital spend only a few minutes visiting family members in the wards. Patients stated that they came to the hospital for their clinic appointment and did not intend to visit the HCG. Staff also reported being busy treating patients in the ward and managing work in the office. Regarding the physical design, $64.4 \%$ of respondents in $\mathrm{H} 2-\mathrm{C} 3$ and $24.4 \%$ of respondents in $\mathrm{H} 3-\mathrm{C} 2$ mentioned that there was no signage directing them to the HCG. Surprisingly, none of the respondents in $\mathrm{H} 1-\mathrm{C} 1$ mentioned this issue because this hospital allocated proper signage to the HCG and the location of the HCG is nearby the main lobby. Moreover, a higher number of respondents in the $\mathrm{H} 2-\mathrm{C} 3$ mentioned that they did not know the location of the HCG compared to the other HCGs because the location is too secluded from the main hospital lobby. Issues related to the uncomfortable and lack of seating and uninteresting landscape elements were highlighted the most by the respondents in the H3-C2 compared to other HCGs. Another barrier that deters them from visiting the HCG is the lack of accessibility, such as locked doors in $\mathrm{H} 2-\mathrm{C} 3$ and $\mathrm{H} 3-\mathrm{C} 2$. Difficult access for wheelchair users is also one factor contributing to the non-visitation to the HCG. More respondents in both $\mathrm{H} 2-\mathrm{C} 3(40 \%)$ and $\mathrm{H} 3-\mathrm{C} 2$ (17.8\%) were concerned about their safety to visit the HCG and worried if they were not allowed to visit the HCG. Only $2.2 \%$ of respondents feel insecure to visit the $\mathrm{H} 1-\mathrm{C} 1$. In terms of the microclimate, some respondents complained about the weather outside, which was too hot 
and not comfortable for them to stay in the HCG: H2-C3 (24.4\%), H1-C1 (6.7\%), and H3-C2 (6.7\%). Some respondents also complained regarding the lack of shade and breeze in the HCGs (See Figure 7).

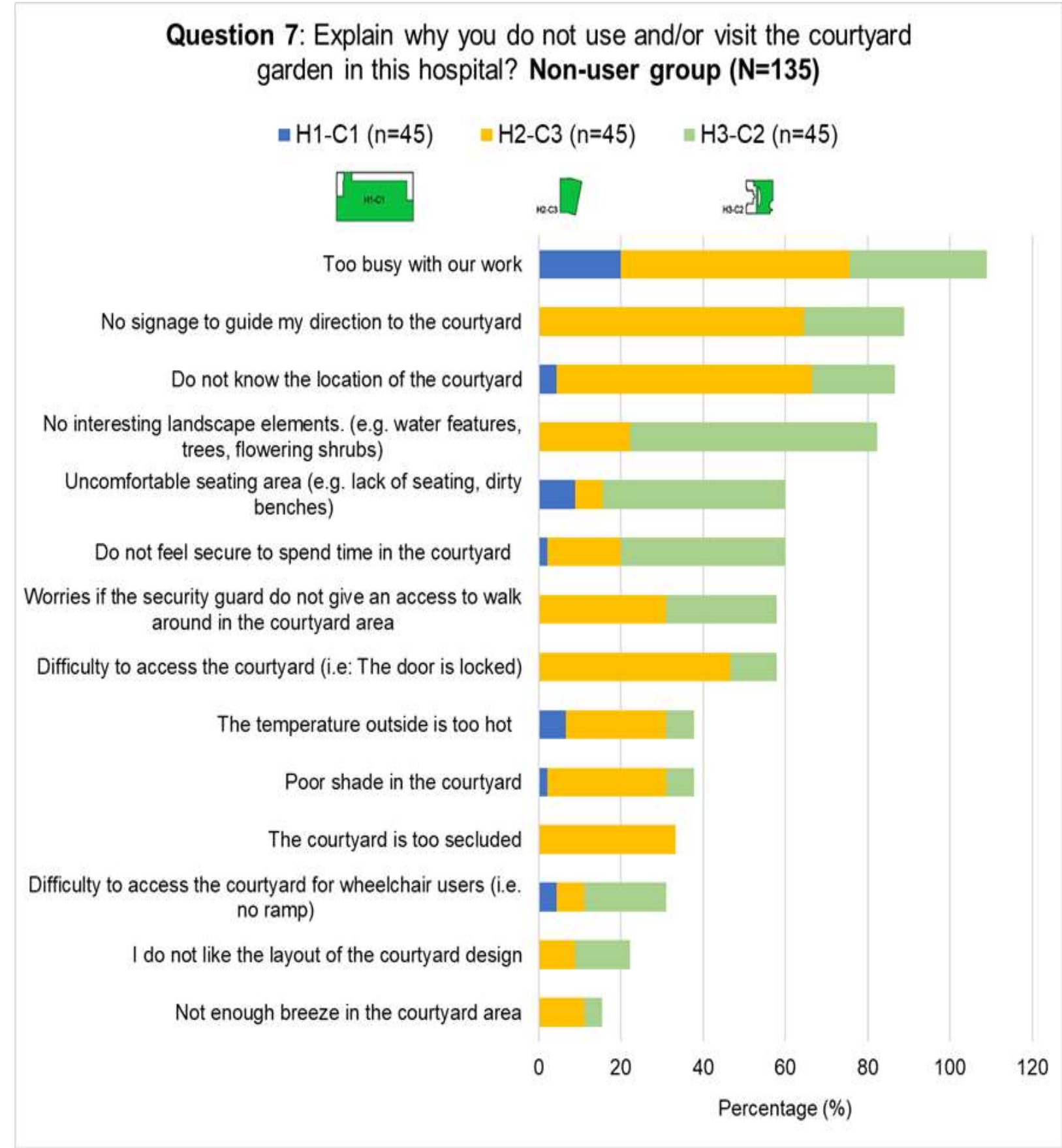

Figure 7: Factors resulted in the non-visitation to the HCG

\subsection{Discussion}

\subsection{Perceived restorative score in relation to the SRT and ART theory}

The perceived restorative scores among users in the three different sites were analysed to examine which HCG was perceived to evidence the highest restorative score. First, the results from the survey questions related to the factors that encouraged them to visit the HCG were arranged according to their components of two important theories of restorative environment, which are Attention Restorative Theory (ART) (Ulrich, 1999) and Stress Reduction Theory (SRT) (Kaplan and Kaplan,1989) (See Table 3). 
Table 3: Perceived restorative based on Attention Restorative Theory (ART) and Stress Reduction Theory (SRT)

\begin{tabular}{ll}
\hline THEORY OF RESTORATIVE ENVIRONMENT & SURVEY QUESTION \\
$\begin{array}{l}\text { ART - Attention restorative theory } \\
\text { SRT - Stress reduction theory }\end{array}$ & Question 19: Factors that encourage you to visit the HCG? \\
\hline $\begin{array}{l}\text { Fascinating (ART) and } \\
\text { Natural distraction (SRT) }\end{array}$ & $\begin{array}{l}\text { I want to enjoy the garden. } \\
\text { I want to cope with my worries. } \\
\text { I want to relax and rest. }\end{array}$ \\
\hline Being away (ART) & I want refuge from the things that distract me. \\
\hline I want to get away from my everyday routine. \\
Compatibility (ART) and & I want to contemplate and find some privacy \\
\hline Iovement and exercise (SRT) & I want to let my child play in the courtyard. \\
\hline Social support (SRT) & I want to do physical exercise. \\
\hline
\end{tabular}

The results of the perceived restorative score based on ART and SRT theory showed that the main factors which encouraged users to visit the HCG related to the components of natural distraction (SRT) and fascination (ART) in which they wanted to enjoy the garden, cope with their worries, and refresh their mind as well as to relax and rest in the HCGs (See Figure 8).

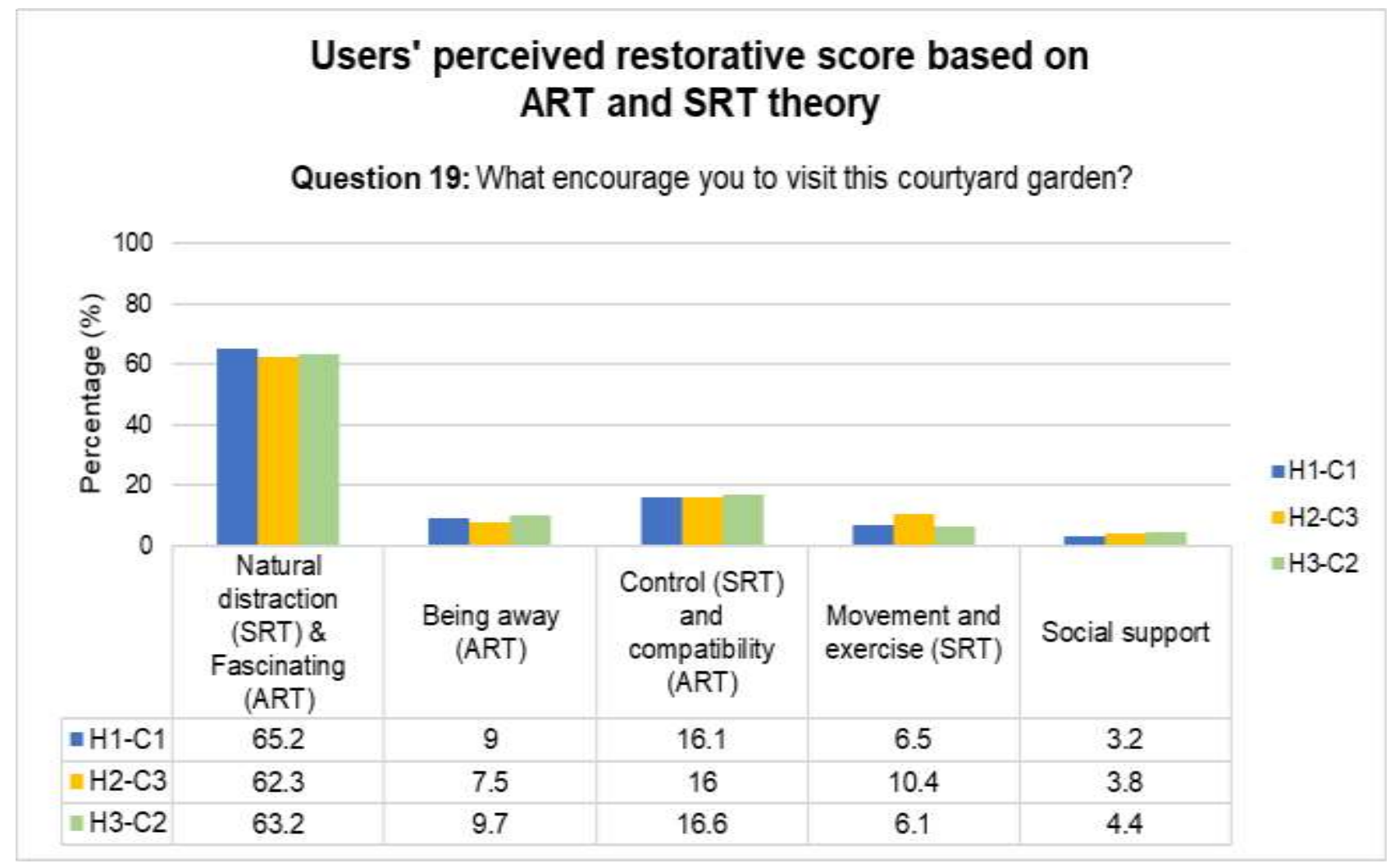

Figure 8: Percentage of the perceived restorative score of each case study site

According to SRT theory, 'natural distraction' is one of the critical components of a restorative environment. This included providing access to nature such as plants, flowers, water, and the sounds of nature. Based on ART theory, 'fascinating' is related to access to the interesting elements in the setting such as flora, fauna, water, play and light. This suggests that users in the hospital context have a strong desire to be in contact with nature and to find a place where they can rest, relax, refresh their minds, cope with worries, and enjoy the outdoor garden. HCG design has a lack of variety in terms of seating facilities, an insufficient amount of greenery and shade in the HCG, which might affect users' experiences and levels of comfort. This study suggested that HCG that offers a better seating choice, interesting landscape elements (e.g., vegetations and water features), and a comfortable microclimate (i.e. shaded and breezier environment) could 
encourage more people to visit and spend time in the HCG. Several previous studies have revealed the impact of vegetations in reducing HCG temperature (Ghaffarianhoseini et al., 2019; Taleghani, 2018; Morakinyo et al., 2016; Shashua-Bar et al., 2011).

Moreover, Cooper Marcus and Sachs (2014) suggested that the best practice for an outdoor garden was to have at least a ratio of 70:30 for vegetation and hardscape, respectively. It was also found that the outdoor garden that has a high amount of greenery was found to be more restorative and appealing to its users (Jiang et al., 2018; Reeve et al., 2017; Shukor et al., 2012). Looking at the overall results on both factors affecting the visitation and non-visitation, $\mathrm{H} 1-\mathrm{C} 1$ evidenced a better restorative environment than the other case study sites. This emphasised the importance of careful planning and ongoing maintenance of the existing facilities in the HCGs to provide a better and more comfortable environment for the intended users.

\subsection{Conclusion and recommendations}

In conclusion, this study found that the factors affecting the staff, patients, and visitors to spend time in the HCG are due to their desire of being in a natural environment to relax and rest, refresh their mind, and stay away temporarily from the hospital's indoor areas. This study also revealed five significant key findings that refrained people from visiting the HCG: i) busy life routines; ii. improper hardscape and softscape design; iii. accessibility issue for both normal and disabled people; iv. concern on safety issues; and v. unshaded and less breezy microclimate. Therefore, this study recommended that the HCG should not only be designed to achieve better environmental design but also be able to promote a restorative environment that can help to reduce the stress and mental fatigue of patients, staff, and visitors. All crucial aspects, such as physical, environmental, social, and operational aspects, are crucial components of effective HCG design that need to be considered when designing the future HCG. This study acknowledged that only a small sample of HCG users from all the study sites was involved in the survey interview. It is important to note that the number and variation of sample size were based on the general population of the HCG users and non-users who were on-site during the fieldwork. However, if there were no time and budget constraints, it would be more fruitful to recruit an equal sample of visitors, staff, and patients as the representative sample in each study site to ensure more diverse feedback from different groups so that the results could be generalised. Looking at the current issue of indoor air quality and mental health during the Pandemic Covid-19, future studies could focus on how to redesign the HCG that not only meet the intended environmental and restorative roles but also able to respond to the physical distancing measures in controlling the spread of COVID-19 in public outdoor spaces.

\section{Acknowledgements}

The authors would like to thank the Malaysian Ministry of Higher Education and the Universiti Sains Islam Malaysia (USIM) for funding this study. The authors would also express gratitude to the Malaysian Medical Research Education Centre (MREC) for granting research ethics approval to carry out this research (KKM/NIHSEC/P17-1640 (5)). Thanks to those who had involved and contributed to this research.

\section{Paper Contribution to Related Field of Study}

This study contributes to the field of study in the environmental and behavioural study on factors related to the utilisation of the outdoor spaces. From a bigger perspective, this findings study is useful for any related field which focuses on the restorative environments in other building typologies of a tropical climate. Finally, the research findings were instrumental in formulating the framework for an effective courtyard design for a future healthcare facility which will be useful to the researchers, architects and landscape architects, facility managers and policymakers.

\section{References}

Adnan, S. N. F. (2016) Design recommendations for a restorative green outdoor environment at Serdang hospital. (Unpublished Master thesis, University Putra Malaysia).

Almhafdy, A., Ibrahim, N., Ahmad, S. S., \& Yahya, J. (2013). Courtyard Design Variants and Microclimate Performance. In Procedia - Social and Behavioral Sciences (Vol. 101, pp. 170-180). Elsevier. https://doi.org/10.1016/j.sbspro.2013.07.190

Almhafdy, A., Ibrahim, N., Ahmad, S. S., \& Wan Salleh, W. M. N. (2014). Courtyard as microclimatic modifier: Experimental study on actual site. Applied Mechanics and Materials, 567, 14-19.

Amat, N. S. A. (2017). Preference for green outdoor environment over indoor spaces by cardiac survivors with walking as a rehabilitative activity. Unpublished Master Thesis, Universiti Putra Malaysia.

Berto, R. (2005). Exposure to restorative environments helps restore attentional capacity. Journal of Environmental Psychology, 25(3), $249-259$. https://doi.org/10.1016/j.jenvp.2005.07.001

Cooper Marcus, C., \& Barnes, M. (1995). Gardens in healthcare facilities: Uses, therapeutic benefits, and design recommendations. Concord, CA: Center for Health Design.

Cooper Marcus, C., \& Sachs, N. A. (2014). Therapeutic Landscapes: An Evidence-Based Approach to Designing Healing Gardens and Restorative Outdoor. New Jersey, Canada: John Wiley and Sons. 
Creswell, J. W. (2015). A concise introduction to mixed methods research (Eds). SAGE Publication Ltd. Retrieved from https://books.google.com.au/books/about/A_Concise_Introduction_to_Mixed_Methods.html?id=KeyRAwAAQBAJ\&pgis=1

Đukanović, Z., Marić, J., \& Giofrè, F. (2017). Evaluation of hospital outdoor spaces through users' participation analysis. Facta Universitatis, Series: Architecture and Civil Engineering, 15(1), 73-84.

Ghaffarianhoseini, A., Berardi, U., Ghaffarianhoseini, A., \& Al-Obaidi, K. (2019). Analysing the thermal comfort conditions of outdoor spaces in a university campus in Kuala Lumpur, Malaysia. Science of the Total Environment, 666, 1327-1345. https://doi.org/10.1016/j.scitotenv.2019.01.284

Gonzalez, M. T., Hartig, T., Patil, G. G., Martinsen, E. W., \& Kirkevold, M. (2011). A prospective study of group cohesiveness in therapeutic horticulture for clinical depression. International journal of mental health nursing, 20(2), 119-129.

Hartig, T. \& Staat, H. (2004). 'Restorative environments', Encyclopedia of Applied Psychology, 3, pp. 273-279.

Honold, J., Lakes, T., Beyer, R., \& van der Meer, E. (2016). Restoration in urban spaces: Nature views from home, greenways, and public parks. Environment and behavior, 48(6), $796-825$.

Huang, Q., Yang, M., Jane, H. ann, Li, S., \& Bauer, N. (2020). Trees, grass, or concrete? The effects of different types of environments on stress reduction. Landscape and Urban Planning, 193. https://doi.org/10.1016/j.landurbplan.2019.103654

Idris, M. M., Sibley, M. and Hadjri, K. (2018) 'Investigating Space Use Patterns in a Malaysian Hospital Courtyard Garden: Lessons from real-time observation of patients, staff and visitors', Environment-Behaviour Proceedings Journal, 3(8), p. 32. doi: 10.21834/e-bpj.v3i8.1413.

Idris, M. M., \& Sibley, M. (2019). What are users' perceptions of the hospital courtyard garden and how satisfied are they with it?. Asian Journal of Environment-Behavior Studies, 4, 60-75.

Idris, M. M. (2020). Holistic Multi-Methods Approach in the Investigation of Environmental and Restorative Functions of Courtyard Gardens in Malaysian Public Hospitals (Doctoral dissertation, University of Sheffield).

Jang, H. S., Jeong, S. J., Kim, J. S., \& Yoo, E. (2020). The role of visitor's positive emotions on satisfaction and loyalty with the perception of perceived restorative environment of healing garden. Journal of People, Plants, and Environment, 23(3), 277-291. https://doi.org/10.11628/ksppe.2020.23.3.277

Jiang, S., Staloch, K., \& Kaljevic, S. (2018). Opportunities and barriers to using hospital gardens: Comparative post occupancy evaluations of healthcare landscape environments. Journal of Therapeutic Horticulture, 28(2), 23-56.

Kaplan, S. (1995) 'The restorative benefits of nature: Toward an integrative framework', Journal of Environmental Psychology, 15(3), pp. 169-182. doi: 10.1016/0272 4944(95)90001-2.

Kaplan, R. \& Kaplan, S. (1989). The Experience of Nature: A Psychological Perspective. Cambridge: Cambridge University Press. doi: 10.1037/030621.

Karanikola, Paraskevi, et al. "Indoor and Outdoor Design in Healthcare Environments: The Employees' Views in the General University Hospital of Alexandroupolis, Greece." Environments 7.8 (2020): 61.

Kim, W., Lim, S. K., Chung, E. J., \& Woo, J. M. (2009). The effect of cognitive behavior therapy-based psychotherapy applied in a forest environment on physiological changes and remission of major depressive disorder. Psychiatry investigation, 6(4), 245.

Morakinyo, T. E., Adegun, O. B., \& Balogun, A. A. (2016). The effect of vegetation on indoor and outdoor thermal comfort conditions: Evidence from a microscale study of two similar urban buildings in Akure, Nigeria. Indoor and Built Environment, 25(4), 603-617. https://doi.org/10.1177/1420326X14562455

Pasha, S. (2013). Barriers to garden visitation in children's hospitals. HERD: Health Environments Research \& Design Journal, 6(4), 76-96.

Naderi, J. R., \& Shin, W. H. (2008). Humane design for hospital landscapes: A case study in landscape architecture of a healing garden for nurses. HERD: Health Environments Research \& Design Journal, 2(1), 82-119.

Reeve, A., Nieberler-Walker, K., \& Desha, C. (2017). Healing gardens in children's hospitals: Reflections on benefits, preferences and design from visitors' books. Urban Forestry and Urban Greening, 26, 48-56. https://doi.org/10.1016/j.ufug.2017.05.013

Sachs, N. A. (2019). A breath of fresh air: outdoor spaces in healthcare facilities can provide clean air and respite. HERD: Health Environments Research \& Design Journal, 12(4), 226-230.

Said, I., Salleh, S. Z., Bakar, M. S. A., \& Mohamad, I. (2005). Caregivers' Evaluation On Hospitalized Children's Preferences Concerning Garden And Ward. Journal of Asian Architecture and Building Engineering, 4(2), 331-338.

Samad, N. A. A. and Rahim, A. A. (2014). Optimum Healing Spaces of Public Areas for Children Aged 4 to 12 in Malaysian Hospitals. Journal of Architecture, Planning and Construction Management, 4(2).

Shashua-Bar, L., Pearlmutter, D., \& Erell, E. (2011). The influence of trees and grass on outdoor thermal comfort in a hot-arid environment. International journal of climatology, 31(10), 1498-1506. 
Shukor, S. F. A. . (2007) Design Characteristics of Healing Garden for Down'S Syndrome Children in Malaysia. (Master Dissertation, Universiti Putra Malaysia).

Shukor, S., Stigsdotter, U. K., Faris, S., \& Nilsson, K. (2012). A Review of Design Recommendations for Outdoor Areas at Healthcare Facilities. Journal of Therapeutic Horticulture, 22(2), 32-47.

Staats, H., Kieviet, A., \& Hartig, T. (2003). Where to recover from attentional fatigue: An expectancy-value analysis of environmental preference. Journal of environmental psychology, 23(2), 147-157.

Taleghani, M. (2018). Outdoor thermal comfort by different heat mitigation strategies: A review. Renewable and Sustainable Energy Reviews, 81, 2011-2018. https://doi.org/10.1016/j.rser.2017.06.010

Thompson, C. W., Roe, J., Aspinall, P., Mitchell, R., Clow, A., \& Miller, D. (2012). More green space is linked to less stress in deprived communities: Evidence from salivary cortisol patterns. Landscape and urban planning, 105(3), 221-229.

Tseung, V., Verweel, L., Harvey, M., Pauley, T., \& Walker, J. (2021). Hospital Outdoor Spaces: User Experience and Implications for Design. HERD: Health Environments Research \& Design Journal, 19375867211045403.

Ulrich, R. S. (1984). View through a window may influence recovery from surgery. Science, 224(4647), 420-421.

Ulrich, R. S., Simons, R. F., Losito, B. D., Fiorito, E., Miles, M. A., \& Zelson, M. (1991). Stress recovery during exposure to natural and urban environments. Journal of environmental psychology, 11(3), 201-230.

Ulrich, R. S., Bogren, L., Gardiner, S. K., \& Lundin, S. (2018). Psychiatric ward design can reduce aggressive behavior. Journal of Environmental Psychology, $57,53-66$.

Ulrich, R. S., Cordoza, M., Gardiner, S. K., Manulik, B. J., Fitzpatrick, P. S., Hazen, T. M., \& Perkins, R. S. (2020). ICU patient family stress recovery during breaks in a hospital garden and indoor environments. HERD: Health Environments Research \& Design Journal, 13(2), 83-102.

Ulrich, R. S. (1981). Natural versus urban scenes: Some psychophysiological effects. Environment and behavior, 13(5), 523-556

Ulrich, R. S. (1991, January). Effects of interior design on wellness: theory and recent scientific research. In Journal of Health Care Interior Design: Proceedings from the... Symposium on Health Care Interior Design. Symposium on Health Care Interior Design (Vol. 3, pp. 97-109).

Ulrich, R. S. (1999). Effects of gardens on health outcomes: Theory and research. Healing gardens: therapeutic benefits and design recommendation. Verderber, S., \& Reuman, D. (1987). Windows, views, and health status in hospital therapeutic environments. Journal of Architectural and Planning Research, 120-133.

Wilson, E. O. (1984). Biophilia. Harvard University Press. 